\title{
QUE LIBERDADE? UMA ANÁLISE DA CRIMINALIZAÇÃO DAS SERVIDORAS DOMÉSTICAS CARIOCAS (1880-1930)
}

Which freedom? An analysis of the criminalization of the domestic workers from Rio de Janeiro (1880-1930)

Qué libertad? Un análisis de la criminalización de las empleadas domésticas de Río de Janeiro (1880-1930)

NATÁlia BATISTA PEÇANHA ${ }^{\mathrm{I}^{*}}$

' Universidade Federal Rural do Rio de Janeiro (UFRRJ), Rio de Janeiro - RJ, Brasil.

Doutora pela Universidade Federal Rural do Rio de Janeiro (UFRRJ). (nataliahist@hotmail.com), ORCID iD: https://orcid.org/0000-0003-2013-106X

Artigo recebido em 15 de novembro de 2018 e aceito para publicação em 12 de fevereiro de 2019. 


\section{RESUMO}

0 presente artigo propõe uma discussão que articula diversas áreas dos saberes historiográficos: a história do crime, dos mundos do trabalho, e do gênero. Ao propor tal tarefa, pretendemos analisar o processo de criminalização do serviço doméstico, sobretudo de suas trabalhadoras, pensando em uma perspectiva interseccional, ao analisar como raça, classe e gênero foram decisivos para a consolidação de estigmas disseminados pela imprensa carioca de fins do século XIX e princípios do XX.

PALAVRAS-CHAVE: Serviço doméstico; Criminalidade; Raça; Classe; Gênero.

\section{ABSTRACT}

The present article proposes a discussion that deals with many different areas of historiographical knowledge: the history of crime, of the realms of labor, and of gender. By proposing this task, we intend to analyze the process of criminalization of domestic service, especially of the domestic workers, through a intersectional perspective, by analyzing were crucial for the consolidation of stigmas disseminated by the Rio de Janeiro press of the end of the 19 th century and beginning of the 20th century.

KeYWORDS: Domestic service; Criminality; Race; Class; Gender.

\section{RESUMEN}

El presente artículo propone una discusión que articula diversas áreas de los saberes historiográficos: la historia del crimen, de los mundos del trabajo, y del género. Al proponer tal tarea, pretendemos analizar el proceso de criminalización del servicio doméstico, sobretodo de sus trabajadoras, pensando en una perspectiva interseccional, al analizar como raza, clase y género han sido decisivos para la consolidación de estigmas diseminados por la prensa de Río de Janeiro de finales del siglo XIX y principios del siglo XX.

Palabras ClaVe: Servicio doméstico; Criminalidad; Raza; Clase; Género. 


\section{INTRODUÇÃO}

$\mathrm{O}$ "negro não se aproximará da liberdade até que esse distintivo odioso da escravidão e do medievalismo tenha sido reduzido a menos de 10\%" (Du Bois, 1920: 115). Esta é a conclusão de Du Bois em The Servant in the House, ensaio escrito na década de $1920^{1}$ no qual ele apresenta suas críticas em relação à suposição de que o serviço doméstico seria um caminho natural para os negros. Para ele, apesar do decréscimo da participação negra no serviço doméstico ao longo do século XIX, as marcas da escravidão só findariam efetivamente quando menos de $10 \%$ da população negra estivesse empregada neste serviço. Cerca de 90 anos depois, segundo estudos da Organização Internacional do Trabalho (OIT) elaborados entre os anos de 2010 e 2011, 7,2 milhões de pessoas foram categorizadas como servidoras domésticas no Brasil, das quais 6,9 eram mulheres. Entre elas, 61,7\% eram negras. (Silva, Silva, Fernandes, Nunes, Balduíno, Faria e Gabriela,2012: 56)

Depois de 130 anos da abolição da escravidão, um grande número de mulheres negras ainda trabalham como servidoras domésticas, como os dados destacados nos demonstram. Se tal atividade representa as marcas da escravidão no que tange às dinâmicas das relações de trabalho, tanto no que diz respeito à domesticidade associada a ela quanto à baixa remuneração e à feminilização, tais marcas também mostram-se presentes na suspeição associada a tal classe de trabalhadoras/es.

Em ação ajuizada perante a Vara do Trabalho de Patrocínio, um casal de patrões foi condenado ao pagamento da indenização, típica de dispensa sem justa causa, e de $R \$ 3.000,00$ por danos morais pela acusação de furto sem provas dirigidas à sua empregada doméstica. ${ }^{2}$ Tal suspeição sobre as empregadas domésticas, principalmente as trabalhadoras negras, não é fruto de um caso isolado, localizado em um tempo específico, mas um processo que vem se desenhando desde fins do século XIX, sobretudo como fruto de políticas emancipacionistas que culminaram com o fim da escravidão e com o problema de como lidar com uma população negra liberta.

Em Onda negra, medo branco, Célia Maria Marinho de Azevedo (1987) faz uma análise do processo de criação do medo em relação ao negro e à negra no momento da instituição de um mercado de trabalho livre. As ansiedades e preocupações de "homens bons" com relação ao fim da escravidão, ao futuro de um mercado de trabalho livre e ao que fazer com os negros com o fim da "polaridade senhor-escravo" (ibidem: 33), nortearam agendas políticas, e "pedagogias" elaboradas pela intelligentsia e ratificadas pela "racionalidade" científica e também por pautas jornalísticas que alimentavam o medo e a atenção em relação à classe trabalhadora. ${ }^{3}$ 
De acordo com James C. Scott, o estabelecimento das relações de dominação pressupõe simultaneamente resistências, uma vez que, para a sua implantação e permanência, é necessário o uso do poder, muitas vezes contra a vontade dos subordinados. Assim, a fim de manter a dominação, é necessário um trabalho de "consolidação, ajustamento e perpetuação" (Scott, 2013: 83). E parte deste trabalho, feito pela construção de representações simbólicas de dominação e de representações de poder, consolida e manifesta uma ordem hierárquica.

Partindo dessa perspectiva, a imprensa carioca pode ser entendida como um discurso público no qual as representações simbólicas dominantes podem exercer a função de criar uma aparência de unanimidade. ${ }^{4}$ Neste sentido, é representada, no caso do serviço doméstico, uma imagem unânime do perigo e, por conta disso, surge a necessidade de se controlar e ordenar essa classe de trabalhadoras/es, transformando, em grande parte, as manifestações públicas de insubordinação das/os criadas/os em atos criminosos, de desajustados que precisavam ser contidos. Ou seja, cria-se um espectro de medo em relação as/os trabalhadoras/es domésticas/ os a fim de justificar qualquer forma de controle e regulamentação da dita atividade.

\section{A PRODUÇÃO DO DISCURSO PÚBLICO ACERCA DA CRIMINALIDADE NO SERVIÇO DOMÉSTICO}

A dominação sempre envolve tentativas de objetificar o grupo subordinado. "Na condição de sujeitos, as pessoas têm o direito de definir sua própria realidade, estabelecer suas próprias identidades, nomear sua história", afirma Bell Hooks [...]. "Na condição de objetos, a realidade de uma pessoa é definida por outras, a identidade de uma pessoa é criada por outras, a história de uma pessoa é nominada apenas de modo a definir o relacionamento de alguém com aqueles que estão sujeitos" [...]. 0 tratamento dispensado às empregadas domésticas negras dos Estados Unidos exemplifica as muitas formas que a objetificação pode tomar. Fazer com que as mulheres negras trabalhem como se fossem animais ou "mulas do mundo" representa uma forma de objetificação. Rituais de deferência, como chamar de "meninas" as trabalhadoras domésticas negras, permitem que os empregadores tratem suas empregadas como crianças, como seres humanos menos capazes. A objetificação pode ser tão grave que o Outro simplesmente desaparece. (Collins, 2009: 71; tradução livre) ${ }^{5}$

Nas palavras de Patricia Hill Collins, podemos perceber a intersecção de gênero, classe e raça como elementos que, juntos, fazem com que o sujeito que incorpora essa tríade seja alvo de tentativas de objetificação pelo grupo dominante. As imagens das mulheres negras e pobres passam a ser construídas e controladas socialmente, refletindo interesses de grupos dominantes em mantê-las na subordinação (idem)Pensar o papel da imprensa e da literatura na objetivação da mulher negra é importante para que possamos compreender como imagens 
racializadas dessas personagens são disseminadas por uma parcela da população que consome esse discurso do medo em relação às trabalhadoras do serviço doméstico, discurso que se tornava global, sobretudo, com o avançar do capitalismo e a implementação de diversas formas de relações de trabalho, em que a obediência do/a trabalhador/a era ameaçada por desordens e resistências (Linebaugh; Rediker, 2008: 11-12; 87)

A preocupação com relação à classe das/os trabalhadoras/es mostrava-se como algo visível no mundo capitalista, tornando o serviço doméstico uma atividade que foi alvo de constantes argumentos acerca da idoneidade e periculosidade de trabalhadoras/es. Desta forma, a questão da classe e do gênero, uma vez que feminização do serviço doméstico foi um dos motivos para a sua degradação, revela-se um ponto fundamental para o entendimento das diversas representações negativas desta atividade. Entretanto, sobretudo para o caso brasileiro, a questão racial andou junto, e, muitas vezes, determinou políticas de controle e disseminação de representações negativas sobre os comportamentos e práticas sociais das trabalhadoras negras.

Ao serem analisados os discursos disseminados acerca do serviço doméstico carioca no período selecionado de 1880 a 1930, é necessário, em primeiro lugar, ter em mente que a maioria dos discursos propalados sobre a mulher é produzida por homens. Além disso, o discurso elaborado sobre a mulher negra é produzido majoritariamente por pessoas brancas, de uma elite letrada, que projetam preconceitos, estereótipos raciais e erotização sobre os corpos dessas personagens, muitas vezes amparadas por saberes médicos ou jurídicos.

Ao longo do século XIX, as imagens das mulheres negras foram utilizadas para representar patologias, corrupção e primitivismo, " configurando o corpo feminino negro como doente e, portanto, nocivo à saúde de uma nação em construção" (Xavier, 2012: 67). Segundo Giovana Xavier, é nesse contexto que tipologias literárias, tais como a da bela mulata, da crioula feia, da escrava infiel, surgiram (idem)

Periódicos como $O$ Rio Nu surgiam a fim de associar o corpo da mulher negra aos excessos sexuais, num momento em que uma política sexual de higienização da família brasileira ganha contornos de política pública. ${ }^{6}$ 


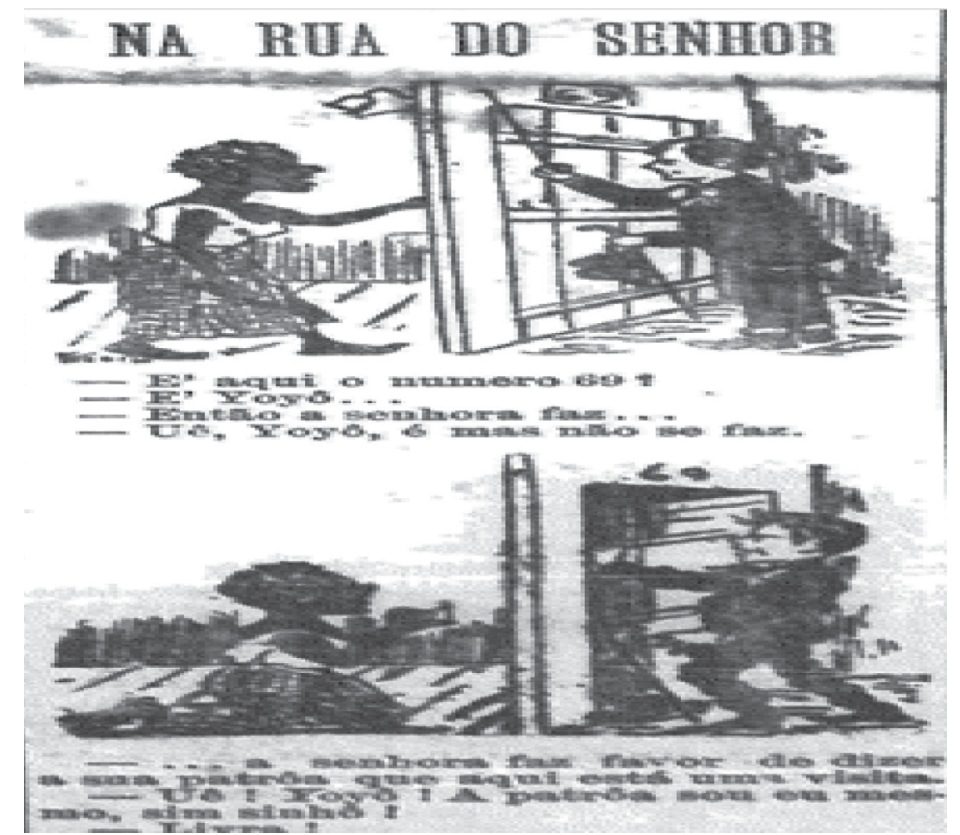

Figura 1: Charge "Na RUA DO SENHOR". O Rio Nu, Rio de Janeiro, 23 set. 1899, p. 1. Fonte: PEÇANHA, Natália Batista. "Regras de civilidade": tecendo a masculinidade do smart nas páginas d'O Rio Nu (1898-1916). Dissertação de mestrado. Rio de Janeiro: PPGH-UFRRJ. 2013.

Na charge destacada das páginas de um jornal de "gênero alegre", 7 observamos a representação de uma criada negra associada à prostituição. ${ }^{8}$ Ela reside em uma casa de número 69, número sugestivo de uma espécie de prática sexual. Recebe um cliente e logo se põe em joelhos, sugerindo que se preparava para algum ato sexual, provavelmente o sexo oral. Entretanto, tal cliente a rejeita, provavelmente, por sua cor de pele. Ela é uma mulher negra, sem face, associada a elementos que remetem a símbolos da escravidão (pés descalços e 0 linguajar), o que reforça a ideia de que as experiências e vivências da liberdade não podem ser entendidas apenas como uma "antítese da escravidão, mas como constitutivas e configuradas pelo mundo da escravidão"(Cunha, 2002: 391). Estamos falando de uma charge de 1899, ou seja, 11 anos após a abolição, mas que ainda relaciona as criadas negras à escravidão, assumindo um discurso ideológico de que as escravas domésticas eram afeitas à prostituição (Soares, 1992). A cor, portanto, marca fronteiras sociais. Para despertar os desejos sexuais de um homem branco, o jornal $O$ Rio $N u$, representante de um gênero da imprensa dedicado ao público masculino, não dava face ou personificações sensuais às criadas negras (PEÇANHA, 2013); por outro lado, as faces dessas mulheres eram destacadas em periódicos criminais, nos quais suas imagens eram associadas a delitos como o furto, por exemplo. 


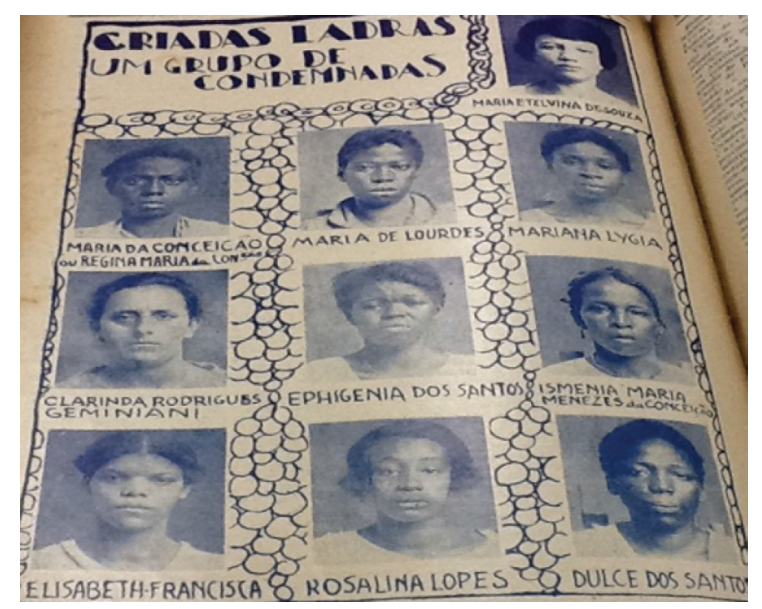

Figura 2: Criadas ladras: um grupo de condemnadas. Fonte: Revista Criminal, 1928a: 52.

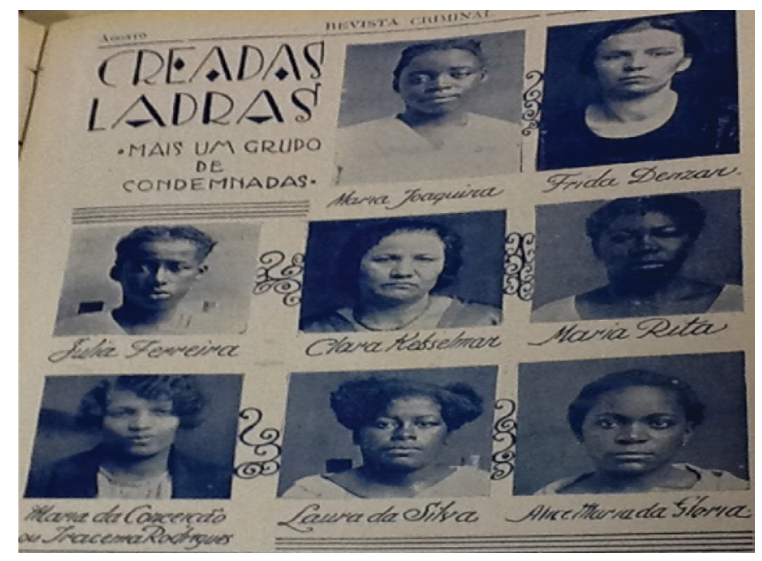

Figura 3: Creadas ladras: mais um grupo de condemnadas. Fonte: Revista Criminal, 1928b: 53.=

Nas duas páginas destacadas da Revista Criminal de agosto de 1928, as faces de 15 mulheres de cor ganham contornos. Apesar de haver três imagens de mulheres brancas (aparentemente estrangeiras e corporificando o "outro", o "outsider"), as criadas negras (nacionais, porém, não as ideais) surgem como a maioria, o elemento que personifica o grupo das "criadas ladras".$^{10}$ Trata-se de mulheres, pobres e de cor, em que a cor da pele transmite uma memória social, não só do passado escravista ou do contanto desses corpos com o degradante mundo do trabalho, como também da constante reatualização do que seu passado representa, gerando, portanto, imagens capazes de representar esses indivíduo socialmente (Cunha, 2002: 535). 
As "criadas ladras" ilustradas nas páginas da Revista Criminal destacavam-se, principalmente, pelas condenações nos artigos 330,11 331, ${ }^{12}$ 196, ${ }^{13}$ e 39914 do Código Penal de 1890, que se referiam a furtos, invasões a domicílios e vadiagem. Por sinal, tratava-se de crimes e contravenções que, somados à embriaguez habitual e à desordem, caracterizavam, de forma generalizada, a imagem que foi sendo construída das/os criadas/os, sobretudo em princípios do século XX, momento em que a classe trabalhadora e certas práticas desempenhadas por ela passam a ser criminalizadas. ${ }^{15}$

A partir da consulta em livros de matrículas na Casa de Detenção da Corte (posteriormente denominada Casa de Detenção do Distrito Federal), na qual selecionamos um mês referente $^{16}$ aos anos de 1880, 1883, 1892, 1912, 1920, e 1929 a 1930, totalizando 415 registros, verificamos um predomínio das contravenções, e menos registros de crimes como furto, por exemplo.

Quadro 1: Infrações cometidas por servidoras/es domésticas/os.

Casa de Detenção da Corte e do Distrito Federal (1880, 1883, 1892, 1912, 1920, e 1929 a 1930). Fonte: Livros da Casa de Detenção da Corte e do Distrito Federal. ${ }^{17}$

\begin{tabular}{|c|c|c|c|}
\hline \multicolumn{4}{|c|}{$\begin{array}{l}\text { Infrações COMetidas pOR SERVIdoras/es domésticas/os. CASA de DetenÇão da CorTe e } \\
\text { CASA de Detenção do Distrito Federal }(1880,1883,1892,1912,1920, \text { e } 1929 \text { a 1930) }\end{array}$} \\
\hline Furto & 5 & Estupro & 2 \\
\hline Arrombamento & 1 & Gatunagem/ratoneiro/roubo & 31 \\
\hline $\begin{array}{l}\text { Foi encaminhada/o à Casa de Detenção } \\
\text { pela Colônia Correcional }\end{array}$ & 4 & Homicídio/tentativa & 4 \\
\hline Ofensas físicas & 16 & Fabrico/porte de arma & 3 \\
\hline Fuga & 5 & $\begin{array}{l}\text { Foi encaminhada à Casa de Detenção por } \\
\text { decisão do juiz }\end{array}$ & 1 \\
\hline Falsificação & 1 & Prática de atos imorais & 2 \\
\hline Quebra/assinatura de termo & 8 & Prostituição & 2 \\
\hline Desacato a autoridade & 5 & Ofensas morais/proferir palavras imorais & 8 \\
\hline Resistência à prisão & 3 & $\begin{array}{l}\text { Contravenções: vadiagem, vagabundagem, } \\
\text { desordem, embriaguez, capoeira e jogo }\end{array}$ & 315 \\
\hline Revogação de liberdade condicional & 9 & Sem informação & 21 \\
\hline
\end{tabular}

A imprensa foi um elemento fundamental para a associação das/os criadas/os à criminalidade, sobretudo ao furto de casas, como fazia a Revista Criminal, divulgando as imagens das criadas ladras. Mulheres, em sua maioria de cor, que dividiam espaço com estrangeiras com as 
alcunhas de "infiéis", "ratas" ou "ladras". Estas, por sua vez, já condenadas por vagabundagem e furto. Entretanto, as fichas de matrícula da Casa de Detenção da Corte, nos mostram que, mais do que cometer furtos ou roubos, as/os criadas/os eram alvo das ações policiais em seu cotidiano de mulheres ou homens que transitavam pelas ruas, seja para desempenhar seus afazeres, seja para vivenciar suas sociabilidades: caminhar por altas horas, tomar suas bebidas em botequins da cidade, manter suas relações amorosas ou flerts e deflagrar uma rixa, por exemplo.

Dos 446 crimes ou contravenções registrados, 36 referiam-se a furtos ou roubos, e 315 a contravenções: vagabundagem, desordem, jogos e capoeira. 0 alto índice de criadas/os recoIhidas/os por vagabundagem (114 casos, especificamente) se destaca, o que pode nos remeter, em primeiro lugar, a um fenômeno "ligado à constituição do espaço urbano" e "também à questão do trabalho" (Souza, 2017: 367), uma vez que a própria noção do termo vadio referia-se a uma necessidade de se "ter clareza de quem seria ou não trabalhador" (ibidem).

Nesse sentido, Mattos destaca que classificações ocupacionais como as esboçadas nos recenseamentos do período foram muito importantes para a diferenciação dos habitantes a partir de sua inserção no mercado de trabalho. A respeito disso é válido salientar que em alguns censos do período que compreende as décadas da virada do século XIX para o XX, como no caso do censo de 1906, os "serviços domésticos" foram reunidos no mesmo segmento que compreendia "classes improdutivas" e os "sem profissão". Para o autor, ao ser "caracterizado como irregular, e nem sempre remunerado (era comum mulheres da casa apresentarem-se sob esta rubrica), 0 trabalho doméstico era desta forma aproximado do não trabalho". (Ibidem: 367-368)

Além de o artigo 399 definir a vadiagem ou vagabundagem como o não exercício de uma "profissão, ofício, ou qualquer mister em que ganhe a vida, não possuindo meios de subsistência e domicílio certo em que habite" (Brasil, 1890), ele estabelece que não são todas as ocupações que podem garantir àqueles que as exercem a alcunha de trabalhador ou trabalhadora. Aquelas/es indivíduas/os que exercessem ofícios que pudessem ofender a moral e os bons costumes, como o meretrício, poderiam ser enquadrados como vadias/os.

Na tabela e no quadro a seguir podemos observar o número de mulheres encaminhadas à Casa de Detenção, bem como o número de ocorrências enquadradas no artigo 399 do Código Penal. 


\section{Quadro 2: Sexo das/os servidoras/es domésticas/os matriculadas/os na Casa de Detenção da Corte (1880, 1883, 1892, 1912, 1920 e 1929 a 1930). Fonte: Livros da Casa de Detenção da Corte e do Distrito Federal.}

\begin{tabular}{|c|c|c|c|c|c|c|c|}
\hline \multicolumn{8}{|c|}{$\begin{array}{l}\text { SeXo das/OS SERVIDORAs/es domésticas/os matriculadas/os na CASA de Detenção } \\
\text { DA CoRTe }(1880,1883,1892,1912,1920 \text { e } 1929 \text { a 1930) }\end{array}$} \\
\hline & 1880 & 1883 & 1892 & 1912 & 1920 & $\begin{array}{r}1929- \\
1930\end{array}$ & Total \\
\hline Homens & 38 & 90 & 91 & & & 11 & 230 \\
\hline Mulheres & 40 & 60 & & 65 & 21 & & 185 \\
\hline Total & 78 & 149 & 92 & 65 & 20 & 11 & 415 \\
\hline
\end{tabular}

Quadro 3: Mulheres enquadradas no artigo 399 do Código Penal de 1890.

(Casa de Detenção da Corte e do Distrito Federal - 1 mês do livro de matrícula de 1880, 1883, 1912 e 1920). Fonte: Livros da Casa de Detenção da Corte e do Distrito Federal.

\begin{tabular}{|c|c|c|}
\hline \multicolumn{3}{|c|}{$\begin{array}{l}\text { Mulheres enquadradas no artigo } 399 \text { do Código Penal de } 1890 . \\
\text { (CASA de Detenção da Corte E do Distrito Federal - } \\
1 \text { mês do livro de matrícula de } 1880,1883,1912 \text { e } 1920)\end{array}$} \\
\hline Período & $\begin{array}{l}\text { Enquadramento no artigo } \\
399\end{array}$ & $\begin{array}{c}\text { Porcentagem em relação ao número total } \\
\text { de mulheres registradas nos livros }\end{array}$ \\
\hline 1880 & 14 & $35 \%$ \\
\hline 1883 & 38 & $64,4 \%$ \\
\hline 1912 & 49 & $75,3 \%$ \\
\hline 1920 & 15 & $71,4 \%$ \\
\hline
\end{tabular}

Como podemos observar, das 185 mulheres registradas na Casa de Detenção, 116 foram enquadradas no artigo 399, o que corresponde a 62,7\% dos casos totais de infrações cometidas por mulheres registradas nos livros de detenção analisados. A recorrência das criadas enquadradas no dito artigo evidencia, em primeiro lugar, os esforços que as autoridades faziam para "higienizar" a cidade, afastando os populares de áreas que se pretendiam "afrancesar", " não só para o desfrute das camadas mais elevadas da população, como para dar mostras da 'civilização' aos capitais e homens estrangeiros que pretendiam atrair" (SOIHET, 1989: 165). Em segundo lugar, o número elevado de criadas enquadradas no delito de vadiagem poderia referir-se à preocupação com a "honra sexual" das mulheres, vista como a base da família, que, por sua vez, seria a base da nação que se pretendia modernizar (Caulfield, 2000: 26). 
Em relação às criadas, as mesmas já geravam preocupações acerca da sua moral e sexualidade desde meados do século XIX. 0 dr. Lassance Cunha, ao defender sua tese de medicina em 1845, enquadrava essas serviçais na "prostituição clandestina", que era aquela desempenhada por mulheres que não viviam exclusivamente da prostituição (Soares, 1992: 28-29). Como o que ocorrera com Julia Kleizer, doméstica húngara, "que há quatro anos", "quando ainda era honesta conheceu o seu patrício Américo Lang que a desonestou levando-a a seguir para o Rio de Janeiro onde a atirou à prostituição", desde então vivendo disso. ${ }^{18}$

Além disso, muitos registros de criadas enquadradas como vadias podem remeter-se àquelas que viviam ou eram suspeitas de viver no meretrício, e que, para fugir da suspeita, diziam ser domésticas, como uma forma de mostrar que exerciam um ofício lícito.

Outro fato que também merece destaque é o baixo índice de registros de furtos ou roubos, frente às outras infrações, contradizendo a ideia comumente proliferada pela imprensa, por literatos, ou por aqueles que propunham a regulamentação do serviço doméstico. Em 441 delitos imputados a criadas/os registrados nos livros de matrícula da Casa de Detenção, o furto correspondia a $1,13 \%$ dos casos, e o roubo correspondia a 7,02\%.

Esse baixo número de registro de furtos e roubos perpetrados por criadas/os fichadas/ os pode, em um primeiro momento, nos fazer pensar que tais crimes não eram uma prática comum entre a criadagem carioca. Entretanto, deve-se ter em mente que esses dados foram os que chegaram às autoridades policiais. Muitos delitos poderiam ocorrer no seio das famílias e acabarem se convertendo em um "costume" "negociável" entre criadas/os e patroas/ões.

Marileide Lázara Cassoli (2017), ao analisar a suspeição de criadas e histórias de liberdade no pós-abolição mineiro, percebe linhas de continuidade entre a escravidão e a liberdade para as primeiras gerações de libertos. Trazendo o caso da criada preta, Virgínia, acusada de roubo de roupas de uso, Marileide questiona o fato de que, apesar de esse costume da criada ser conhecido, ainda assim mantinham-na na mesma função.

Seria Virgínia movida aos atos dos quais foi acusada pela precariedade de sua condição de trabalhadora? Ou podemos vislumbrar resquícios de práticas que remetem ao período escravista e à compreensão do furto como prática legítima por escravos e libertos? Ao analisar o processo crime de furto envolvendo os trabalhadores Hermenegildo João Côrrea e Christino, Sonia Maria de Souza afirma que o furto não era compreendido pelos escravos como uma prática ilegal. (Ibidem: 13)

0 ato de furtar poderia ser entendido como uma compensação pelas baixas remunerações, um direito a uma parcela daquilo que era produzido, ou formas "alternativas" de mostrar alguma insatisfação. ${ }^{19}$ Era uma prática comum durante a escravidão que, possivelmente, se 
estendeu ao pós-abolição, promovendo, por conseguinte, a inclusão de tal costume na categoria de "roubo". (Cassoli, 2017: 13-14; Souza, 2017: 332). Flávia Fernandes de Souza observa que essa redefinição, contribuiu "para a formação de forças policiais que teriam como uma de suas primeiras atribuições o disciplinamento da força de trabalho assalariada" (ibidem: 332).

Uma vez que o crime contra a propriedade, sintetizado na prática do furto, emergiu no século XIX como uma das mais importantes formas de protesto popular no Brasil (Barreiros, 1998: 10), tal prática representava para as classes subalternas uma negação e/ou reação à ideia de propriedade privada capitalista, bem como uma reação ao trabalho disciplinado (ibidem: 12). ${ }^{20}$ Por essa razão, mecanismos de coerção para a contenção de tais práticas e suspeições à classe subalterna foram postos em prática pelas classes dominantes.

Daí justifica-se a suspeição acerca de tais serviçais, mesmo que muitas vezes a certeza não estivesse diretamente relacionada à culpa. Para essas serviçais, as suspeições sobre a sua idoneidade eram o suficiente para indicá-las como as principais suspeitas. Que o diga Celecina.

Celecina Maria da Conceição, criada de uma família residente à rua Barão do Amazonas, em Niterói, devido a uma falsa acusação, quis matar-se, ingerindo creosoto.

A polícia local tomou conhecimento e fez removê-la para o Hospital de S. João Batista. ${ }^{21}$

0 desespero da jovem frente à suspeição que lhe fora imputada mostra-se um dado relevante e comum ao ambiente social em que a classe popular é concebida como "classe perigosa" (Chalhoub, 2001).

Flávia Fernandes de Souza identifica que, no que diz respeito à associação que a imprensa fazia entre criadagem e criminalidade, muitas vezes os discursos não correspondiam à realidade, uma vez que muitas acusações de furtos cometidos por criadas eram noticiadas sem haver a comprovação de culpa da/o serviçal. Muitas vezes, elas/es podiam ser detidas/os com base apenas em acusações, sem provas para comprovar o crime. como o que ocorreu com cozinheira e lavadeira preta Paula Maria Rosa.

Em processo de habeas corpus impetrado a favor de Paula, foi descrito que a mesma "ficou presa ilegalmente por 15 dias por suspeita de furto de galinha". Contudo, segundo o processo, Paula Maria Rosa teria sido erroneamente identificada na Casa de Detenção como "ébria, vagabunda e gatuna incorrigível e reincidente", o que fez com que a criada fosse encaminhada para a Casa de Correção, "na busca de regeneração pelo trabalho útil e honesto" (Souza, 2017: 361-362).

Além disso, havia ainda os casos em que a prisão poderia ser motivada por desavenças entre a ré e o guarda que efetuou a prisão. Como acusa Maria Roza de Souza Retroz, cozi- 
nheira e lavadeira, de 27 anos, natural do Ceará e moradora à rua 25 de Março, número 26, acusada de vadiagem. Maria alega "que foi presa [...] por um guarda soldado do Regimento de Cavalaria, que sendo inimigo dela, paciente promoveu [...] perseguição [...] não tendo recolhido notas de culpa".22

0 advogado do caso, o sr. Irineu Antão de Vasconcellos, ao impetrar o pedido de habeas corpus de Maria Roza e de mais um grupo de detentos, informa que eles estavam constrangidos na liberdade, sendo alguns presos havia mais de 30 dias, "pela prepotência da autoridade do $14^{\circ}$ Distrito Policial". ${ }^{23}$ Ele ainda informa que todos os seus clientes haviam sido autuados pelo crime de vadiagem na $8^{a}$ Pretoria, e acrescenta que o Juiz não devia ignorar

[...] que 0 art. 399 do Cod. Penal é a porta larga sempre aberta à perseguição policial contra os seus desafetos, auto lavrados intra-muros[...], com testemunhas [...] preparadas, funcionários policiais com jurisdição e inferiores hierárquicos da autoridade processante, verdadeiros monstros jurídicos, processos nulos, atestatorios [sic] de uma formicação [sic] imoral onde predominou a parceria do seu autor com os coautores, estes incompatibilizados de dizer a verdade jurídica pela dependência e conservação do emprego exercido, no qual são obrigados a manter a obediência passiva perante a autoridade processante. ${ }^{24}$

Aqui, o que se vê é um artigo penal que dá brechas à suspeição e à perseguição generalizada da classe trabalhadora, bem como ao comportamento abusivo do policiamento carioca, que geralmente era despreparado e acusado de cometer atos violentos e abusivos. ${ }^{25} \mathrm{E}$ estes atos eram direcionados, sobremaneira, a uma população pobre e negra que tinha, sobretudo as mulheres, seus corpos objetificados por uma imprensa que ora exacerbava a sexualidade de tais personagens, com a servidora doméstica tida como aquela que desempenhava "todo o serviço do patrão" 26 . Daí os altos índices de detenções enquadradas no delito da vadiagem. Por outro lado, uma imagem ratificada por um discurso do "medo negro", bem presente na imprensa da segunda metade do século XIX e princípios do XX, em que as resistências negras eram vistas como algo que deveria ser contido e disciplinado, para a segurança da estabilidade social.

Tais relatos e dados selecionados nos permitem verificar de forma empírica como as intersecções de raça, classe e gênero são fundamentais para o processo de criminalização de uma das atividades do mundo do trabalho mais importante para a incorporação da mão de obra feminina brasileira, que é o serviço doméstico. Deve-se deixar claro que as marcas da escravidão mostravam-se presentes no cotidiano dessas mulheres trabalhadoras que precisavam negociar sua "liberdade" em diversos momentos de sua existência. E esta liberdade, apesar da abolição da escravidão, nas palavras de Angela Davis (2016: 100), "eram sombras tão vagas e distantes que era preciso forçar os olhos para vislumbrá-las". 


\section{NOTAS}

1 É evidente que estamos lidando com a declaração de um intelectual negro que está vivenciando o racismo e preconceitos da sociedade americana de inícios do século XX. Apesar de tanto o Brasil quanto os Estados Unidos terem vivenciado a escravidão, não podemos reduzir as experiências dos povos escravizados e libertos dessas regiões de forma homogênea e generalizante. Ao escolher a fala de Du Bois como representativa, considerei que o serviço doméstico era uma preocupação experimentada por populações diversas em diferentes partes do mundo, na passagem do século XIX para o XX. Não que ele propunha a regulamentação de tal serviço, mas, por estar em contato e influenciar o movimento pan-africano, as questões raciais the são caras. 0 serviço doméstico, neste sentido, emergia em sua fala como um espaço laboral em que se evidenciava de forma mais clara as desigualdades de classe, gênero e raça, sendo o serviço doméstico um microcosmo da reprodução estratificada da desigualdade racial vivenciada por mulheres negras, muitas delas imigrantes. Para uma análise das preocupações acerca do serviço doméstico e sua regulamentação em diversas partes do mundo na época aqui abordada, ver Mohapatra (2009), Remedi (2012), e Bujra (2000).

2 AÇÃO AJUIZADA perante a Vara do Trabalho de Patrocínio ( $n^{\circ}$ do processo: 00268-2010-080-03-00-3). Publicada pelo Tribunal Regional do Trabalho da $3^{a}$ Região, 2011. Disponível em: https://trt-3.jusbrasil.com. br/noticias/2393532/acusacao-de-furto-sem-provas-justifica-rescisao-indireta-de-contrato-de-domestica. Acesso em: 23 de outubro de 2018.

3 o serviço doméstico está intrinsecamente ligado ao trabalho escravo no Brasil, onde homens, mulheres e crianças desempenhavam tal atividade "portas adentro" e "portas afora". Todavia, a partir da década de 1860, sobretudo como consequência das leis emancipacionistas, o serviço doméstico passou a ser feito majoritariamente por pessoas livres. Tal mudança na composição do serviço doméstico começou a gerar preocupações na esfera pública principalmente em relação à rotatividade dos seus servidores. Para uma análise mais aprofundada, ver Graham (1992) e Souza (2013; 2010).

4 Sobre o conceito de unanimidade, Scott (2013: 83-84) sustenta que as elites dominantes buscam retratar as ações sociais por meio do discurso público, de forma que seja negada, por omissão, "a possibilidade de uma ação social autônoma por parte dos subordinados".

5 "Domination always involves attempts to objectify the subordinate group. 'As subjects, people have the right to define their own reality, establish their own identities, name their history', asserts Bell Hooks [...]. 'As objects, one's reality is defined by others, one's identity is created by others, one's history is named only in ways that define one's relationship to those who are suject' [...]. The treatment afforded U.S. Black women domestic workers exemplifies the many forms that objectification can take. Making Black women work as if they were animals or 'mules uh de world' represents one form of objectification. Deference rituals such as calling Black domestic workers 'girls' enable employers to treat their employees like children, as less capable human beings. Objectification can be so severe that the Other simply disappears".

6 Sobre a política médica no Brasil Oitocentista, ver: Costa (1977), Machado (1978), e Engel (1989). Sobre o exercício de poder do aparelho jurídico frente à corrupção dos costumes e criminalidade sexual na Belle Époque carioca, ver: Esteves (1989). Ver também Caulfield (2000). 
$7 \mathrm{Na}$ charge, pode-se ler o seguinte diálogo entre a mulher negra e o homem branco:

"-É aqui o número 69?

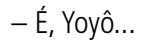

- Então a senhora faz...

- Ué, Yoyô, é mas não se faz...

- ... a senhora faz favor de dizer a sua patrôa que aqui está uma visita.

- Ué! Yoyô! A patrôa sou eu mesmo, sim sinhô!

- Livra!"

8 De acordo com Angela Davis (2016: 100), "Desde o período da escravidão, a condição de vulnerabilidade das trabalhadoras domésticas tem sustentado muitos dos mitos duradouros sobre a 'imoralidade' das muIheres negras. Nesse clássico 'círculo vicioso', o trabalho doméstico é considerado degradante porque tem sido realizado de modo desproporcional por mulheres negras que, por sua vez, são vistas como 'ineptas' e 'promíscuas'. Mas aparentes inépcia e promiscuidade são mitos que confirmam repetidamente pelo trabalho degradante que elas são obrigadas a fazer".

9 Norbert Elias e John L. Scotson (2000) realizam uma análise das tensões que podem existir entre habitantes estabelecidos e os outsiders - estrangeiros que, ao não partilharem dos mesmos valores dos estabelecidos, muitas vezes são mantidos à distância, rejeitados. Mais ainda, de acordo com Angela Davis (2016: 102): "Com frequência, racismo e sexismo convergem - e a condição das mulheres brancas trabalhadoras não raro é associada à situação opressiva das mulheres de minorias étnicas. Por isso, os salários pagos às trabalhadoras domésticas brancas sempre foram fixados pelo critério racista usado para calcular a remuneração das serviçais negras. As imigrantes que eram obrigadas a aceitar o emprego doméstico ganhavam pouco mais do que suas companheiras negras". Sobre a diferença salarial entre nacionais e estrangeiras, ver PEÇANHA, Natália B. "Precisa-se de uma criada estrangeira ou nacional para todo o serviço de casa": Cotidiano e agências de servidoras/es domésticas/os no mundo do trabalho carioca (1880-1930). Tese. Seropédica/RJ: PPGH/UFRRJ, 2018.

10 Lilia M. Schwarcz (1987: 154), ao analisar jornais de São Paulo no final do século XIX, percebe que, na seção de movimento da prisão da cidade, "o negro aparecia (ao lado do imigrante) com grande regularidade".

11 "Art. 330. Subtrair para si, ou para outrem, coisa alheia móvel, contra a vontade do seu dono" (Brasil, 1890).

12 "Art. 331. É crime de furto, sujeito às mesmas penas e guardadas as distinções do artigo precedente: $1^{\circ}$ apropriar-se alguém de coisa alheia que venha ao seu poder por erro, engano, ou caso fortuito; $2^{\circ} \mathrm{Apropriar-se}$ de coisa alheia que the houver sido confiada, ou consignada por qualquer título, com obrigação de a restituir, ou fazer dela uso determinado" (Brasil, 1890).

13 "Art. 196. Entrar à noite na casa alheia, ou em quaisquer de suas dependências, sem licença de quem nela morar" (Brasil, 1890).

14 "Art 399. Deixar de exercitar profissão, ofício, ou qualquer mister em que ganhe a vida, não possuindo meios de subsistência e domicílio certo em que habite; prover a subsistência por meio de ocupação proibida por lei, ou manifestamente ofensiva da moral e dos bons costumes" (Brasil, 1890).

15 Vários pesquisadores se debruçaram em torno da criminalização da classe trabalhadora na passagem do século XIX para o XX, e, dentre os muitos trabalhos podemos destacar Chalhoub (2001) e Kowarick (1987). 
16 A metodologia empregada se justifica pelo fato de cada livro de matrícula ter mais de quinhentas páginas, cada uma contendo duas ou três fichas de matrículas. Devido ao grande número a ser consultado, decidimos selecionar um mês aleatório para que pudéssemos dar conta de um número maior de livros.

17 A numeração e os anos correspondentes aos livros consultados encontram-se na seção de fontes primárias das referências bibliográficas deste artigo.

18 Processo de expulsão..., 1930.

19 Fabiane Poppinigis (2007: 170) ao analisar os caixeiros em processos criminais entre 1890 e 1911, verificou que alguns caixeiros preferiam não esperar para ver seus esforços serem recompensados. Cândido Peixoto que o diga. Em novembro de 1906, sumiu da casa de seu patrão levando 300\$000. A cena descrita por Fabiane Popinigis representa um ápice do rompimento de uma relação marcada por uma afetividade. Muitas vezes, esses caixeiros eram criados nas casas dos patrões, o que não significa que tal relação não fosse altamente hierarquizada e os papéis de subordinação dos criados não fossem bem definidos. Entretanto, pela peculiaridade de tal relação laboral marcada pela familiaridade e afetividade, similar às relações encontradas no serviço doméstico, poderíamos nos deparar com resistências que eram desempenhadas de formas sutis, mas eficazes. De acordo com Jurema Brites (2007: 97-109), a manutenção de um sistema hierárquico de classe, gênero e raça no serviço doméstico brasileiro é reforçada pelo que ela chama de ambiguidade afetiva entre os empregadores e as/os trabalhadoras/es domésticas/os, em que a existência de negociações em relação ao pagamento extrasalarial está marcada por uma alta carga de afetividade, o que não impede a hierarquização de tal relação.

20 De acordo com Linebaugh (1983: 124), acerca da relação entre crime e industrialização na Grã-Bretanha do século XVIII, a monetarização da força de trabalho era muito baixa e assegurada por lei. Ao mesmo tempo, havia diversas formas não monetarizadas de retribuição a um trabalho desempenhado, e uma dessas formas de remunerações era a apropriação, por força do costume, de "sobras" do processo de produção. Ainda sobre este assunto, quando pensamos nestas relações de convivio entre os patrões e os criados, estamos entendendo-as como relações paternalistas, ou seja, "o mundo idealizado pelos senhores, a sociedade imaginária que eles sonhavam realizar no cotidiano". (CHALHOUB, 2003: 61) Uma relação que está menos pautada na simples deferência do criado, no nosso caso, em relação ao patrão, do que na autoimagem que esses senhores faziam de seu poder. Ao pensarmos desta forma, damos margens para as ações de contestação e insubordinações perpetradas cotidianamente por tais personagens. Assim, ao pensarmos as representações das relações entre criados e patrões, sobretudo no que envolve as criadas de sexo feminino, pretendemos identificá-las com uma autoimagem que a sociedade patriarcal criava em relação a estas personagens, mesmo que, na vida prática, pudesse haver manifestações de repúdio e descontentamento a determinadas ações dos patrões por parte dessas serviçais. James Scott (2013), seguindo esta linha de raciocínio, ao analisar as lutas campesinas, identificou o que ele chama de resistências cotidianas, ou seja, reações perpetradas por estes grupos de forma corriqueira, mas sem qualquer confrontação simbólica com a autoridade ou as normas da elite, ou seja, reações estavam ocorrendo muitas vezes sem que o "senhor" as percebesse, sem que sua autoimagem fosse afetada. Ver Chalhoub, 2003: 61; 19; e Thompson, 1998: 78.

21 Uma criada..., 1912: 2.

22 Habeas corpus de Cypriano..., 19100 contato entre guardas e criadas nem sempre poderia ser fruto de perseguições. Em 1906, a Inspetoria Geral da Guarda Civil do Distrito Federal abriu inquérito no qual ficou provado que o guarda da $2^{a}$ classe (n. 389), Manoel Rodrigues Cavalcante, quando de ronda à rua Silveira Martins, abandonou seu posto para penetrar em uma casa de família para ter relações amorosas com uma criada, 
chamada Maria (Processo do réu..., 1906. "No dia 15 de janeiro de 1906, foi a Delegacia da $17^{\text {a }}$ Circunscrição, a Sra. Da. Olga Cunha de Carvalho, residente a rua Marquês de Abrantes n. 94, informar o "desaparecimento de sua casa, na noite de 13 para 14 do corrente a sua criada - menor de $18 p^{\text {a }} 19$ anos de idade, de cor branca e de nome Antonia da Rocha, a qual Ihe foi entregue pelo Dr. Juiz de Direito da Cidade de Campos, desconfiando a mesma Sra ter sido esta sua criada seduzida pelo guarda civil Honorário da Costa Souza, de $\mathrm{n}^{\circ}$. 371, que continuava rondar aquela rua" (Antonia da..., 1906. A liberdade experimentada por tais mulheres poderia aproximá-las das mulheres "desonradas", ou melhor, das prostitutas que eram bastante disputadas por militares e pela guarda, como analisa Cristiana Schettini (2006). Segundo a autora, as prostitutas, além de serem um pretexto para as expressões de rivalidades ou exibição de valentia, "eram parte importante do processo de legitimação pública da autoridade desses homens". Além disso, sob os $\S \S \S \S \S 0 l$ hos das autoridades superiores, essas relações entre guardas de baixo escalão e prostitutas, e aí acrescento também as criadas, demarcavam um distanciamento hierárquico, uma vez que esses guardas eram vistos por seus superiores como "donos de institutos sexuais que se sobreporiam a qualquer ponderação racional" (ibidem: 43-50).

23 Habeas corpus de Maria..., 1910.

24 Habeas corpus de Cypriano..., 1910.

25 Referente ao despreparo do policiamento carioca de princípios do século XX, Marcos Bretas (1997, capítulo 5) informa que o despreparo era uma realidade em boa parte do mundo. Um policial novato tinha pouco ou nenhum treinamento formal, tendo que recorrer aos seus próprios conhecimentos ou à ajuda dos mais experientes.

26 "Todo o serviço do patrão" era uma expressão bastante utilizada, sobretudo em jornais como O Rio Nu, para expressar de forma irônica, a relação existente entre patrão e criada, que muitas vezes extrapolava a relação meramente contratual.

\section{REFERÊNCIAS BIBLIOGRÁFICAS}

Fontes primárias

UMA CRIADA, devido a uma falsa acusação, quis matar-se. A Noite, 14 de fevereiro de 1912, p. 2, ed. 00184. Disponível em: http://memoria.bn.br. Acessado em 27 de maio de 2018.

AÇÃo AJUIZADA perante a Vara do Trabalho de Patrocínio ( $n^{\circ}$ do processo: 00268-2010-080-03-00-3). Publicada pelo Tribunal Regional do Trabalho da $3^{a}$ Região, 2011. Disponível em: https://trt-3.jusbrasil.com. br/noticias/2393532/acusacao-de-furto-sem-provas-justifica-rescisao-indireta-de-contrato-de-domestica. Acesso em: 23 de outubro de 2018.

Antonia Da Rocha (vítima) e Honorário da Costa Souza (réu) AN. Fundo: GIFI - documentação policial/OI. Notação: 6C-178 (1906).

CRIADAS LADRAS: um grupo de condemnadas. Revista Criminal, p. 52, maio 1928 a.

CREADAS LADRAS: mais um grupo de condemnadas. Revista Criminal, p. 53, agosto de 1928b.

BRASIL. Presidência da República. Decreto n 847, de 11 de outubro de 1890. Promulga o Código Penal. Rio de Janeiro: Diário Oficial, 1890. Disponível em: http://legis.senado.gov.br/legislacao/ListaTextoSigen.action?norma=389719\&id=14444059\&idBinario=15629240\&mime=application/rtf. Acesso em: 16 de março de 2019. 
HABEAS CORPUS de Cypriano Telles da Silva, Maria Rita, Georgina da Silva, Corina de Almeida, José Teixeira Gomes da Silva, João Ferreira Maria, Sebastiana Xavier Salles, Maria Roza de Souza Retroz, Saturnino Francisco Teixeira e Manoel Pimenta. Fundo: Supremo Tribunal Federal, 1910. n. 2.906, notação: BR NA, RIO BV.O.HCO.1428 - AN.

HABEAS CORPUS de Maria Rosa. Fundo: Supremo Tribunal Federal, 1910, n. 2.906, notação: BR NA, RIO BV.O.HCO.1428 - AN.

LIVROS DA Casa de Detenção da Corte e do Distrito Federal: MD-LL-011 (1880), MD-LL-0022 (1883), MD-HN-001 (1890), MD-HN-012 (1892), MD-MN-002 (1892), MD-HMN-003 (1912), MD-MN-006, MD-HN-135 (1920), MD-MN-012 (1920), MD-HN-166 (1929-1930). Fundo CDC, BR RJAPERJ CDC e Fundo CDDF, BR RJ APERJ CDDF - APERJ.

PROCESSO DE expulsão do estrangeiro, Américo Lang. Fundo: Série Interior/Estrangeiros - A5, 1930, notação: IJJ7-131-AN.

PROCESSO DO réu Manoel Rodrigues Cavalcante, de 09 de julho de 1906. AN. Fundo: Gifi - documentação policial/OI, 1906, notação: 6C-175.

\section{BIBLIOGRAFIA}

AZEVEDO, Célia Maria Marinho de. Onda negra, medo branco: o negro no imaginário das elites - século XIX. Rio de Janeiro: Paz e Terra, 1987.

BARREIROS, José Carlos. Tradição, cultura e protesto popular no Brasil (1780-1880). Proj. História, São Paulo, n. 16, fev. 1998.

BRETAS, Marcos L. Ordem na cidade: o exercício cotidiano da autoridade policial no Rio de Janeiro: 19071930. Rio de Janeiro: Rocco, 1997.

BRITES, Jurema. Afeto e desigualdade: gênero, geração e classe entre empregadas domésticas e seus empregadores. Cadernos Pagu, n. 29, p. 97-109, jul.-dez. 2007.

BUJRA, Janet. Serving Class. Masculinity and the Feminization of Domestic Service in Tanzania. Londres: Edinburgh University Press for the International African Institute, 2000.

CASSOLI, Marileide Lázara. "Suspeitam das criadas que tinham, principalmente de uma pretinha...": Histórias de liberdade no pós-abolição. Minas Gerais, 1897-1920. In: ENCONTRO ESCRAVIDÃO E LIBERDADE NO BRASIL MERIDIONAL, 8. 2017, Porto Alegre. Anais... Porto Alegre: UFRGS, 2017. p. 13. Disponível em: http:// www.escravidaoeliberdade.com.br/site/images/8encontro/Textos8/marileidelzaracassoli.pdf. Acesso em: 10 de dezembro de 2017.

CAULFIELD, Sueann. Em defesa da honra: moralidade, modernidade e nação no Rio de Janeiro (1919-1940). Campinas: Editora da Unicamp/Centro de Pesquisa em História Social da Cultura, 2000.

CHALHOUB, Sidney. Trabalho, lar e botequim: o cotidiano dos trabalhadores no Rio de Janeiro da Belle Époque. 2 ed. Campinas: Editora da Unicamp, 2001.

. Machado de Assis: historiador. São Paulo: Companhia das Letras, 2003.

COLLINS, Patricia Hill. The Black Feminist Thought: Knowledge, Consciousness, and the Politics of Empowerment. Nova York/Londres: Routledge, 2009. [1. ed. 2000] 
COSTA, Jurandir Freire. Ordem médica e norma familiar. Rio de Janeiro: Graal, 1977.

CUNHA, Olívia Maria Gomes da. Intenção e gesto: pessoa, cor e a produção cotidiana da (in)diferença no Rio de Janeiro, 1927-1942. Rio de Janeiro: Arquivo Nacional, 2002.

DAVIS, Angela. Mulheres, raça e classe. Trad. Heci Regina Candiani. São Paulo: Boitempo, 2016.

DU BOIS, W. E. B. The Servant in the House. In: DarKwater. Voices from within the Veil. Nova York: Harcourt, Brace and Company, 1920.

ELIAS, Norbert; SCOTSON, John L. Os estabelecidos e os outsiders: sociologia das relações de poder a partir de uma pequena comunidade. Rio de Janeiro: Zahar, 2000.

ENGEL, Magali. Meretrizes e doutores. 0 saber médico e a prostituição na cidade do Rio de Janeiro (18451890). São Paulo: Brasiliense, 1989.

ESTEVES, Martha Abreu. Meninas perdidas: os populares e o cotidiano do amor no Rio de Janeiro da Belle Époque. Rio de Janeiro: Paz e Terra, 1989.

GRAHAM, Sandra Lauderdale. Proteção e obediência: criadas e seus patrões no Rio de Janeiro, 1860-1910. Trad. Viviana Bosi. São Paulo: Companhia das Letras, 1992.

KOWARICK, Lúcio. Trabalho e vadiagem - a origem do trabalho livre no Brasil. São Paulo: Brasiliense, 1987.

LINEBAUGH, Peter. Crime e industrialização: a Grã-Bretanha o século XVIII. In. PINHEIRO, P. S. (org). Crime, violência e poder. São Paulo: Brasiliense, 1983.

; REDIKER, Marcus. "A hidra de muitas cabeças": marinheiros, escravos, plebeus e a história oculta do Atlântico revolucionário. Trad. Berilo Vargas. São Paulo: Companhia das Letras, 2008.

MACHADO, Roberto. Danação da norma. Medicina social e constituição da psiquiatria no Brasil. Rio de Janeiro: Graal, 1978.

MOHAPATRA, Prabhu. Informalidade regulamentada: construções legais das relações de trabalho na Índia Colonial (1814-1926). Cadernos AEL, v. 14, n. 26, p. 54-88, 2009.

PEÇANHA, Natália B. "Precisa-se de uma criada estrangeira ou nacional para todo o serviço de casa": Cotidiano e agências de servidoras/es domésticas/os no mundo do trabalho carioca (1880-1930). Tese. Seropédica/ RJ: PPGH/UFRRJ, 2018.

. "Regras de civilidade": tecendo a masculinidade do smart nas páginas d'O Rio Nu (1898-1916). Dissertação de mestrado. Rio de Janeiro: PPGH-UFRRJ. 2013.

POPINIGIS, Fabiane. Proletários de casaca: trabalhadores do comércio carioca, 1850-1911. Campinas: Editora da UNICAMP, 2007.

REMEDI, Fernando J. "Esta descompostura general de la servidumbre". Las trabajadoras del servicio doméstico en la modernización argentina. Córdoba, 1869-1906. Secuencia, n. 84, p. 42-69, set.dez. 2012. Disponível em: http://www.scielo.org.mx/pdf/secu/n84/n84a3.pdf. Acessado em 09 de outubro de 2018.

SCHETTINI, Cristiana. "Que tenhas teu corpo": uma história social da prostituição no Rio de Janeiro das primeiras décadas republicanas. Rio de Janeiro: Arquivo Nacional, 2006. 
SCOTT, James C. A dominação e a arte da resistência: discursos ocultos. Trad. Pedro Serras Pereira. Lisboa: Letra Livre, 2013.

SCHWARCZ, Lilia M. Retrato em branco e negro: jornais, escravos e cidadãos em São Paulo no final do século XIX. São Paulo: Companhia das Letras, 1987.

SILVA, Daniela L; Ionara T Silva; Jaqueline Fernandes; Juliane Nunes; Paula Balduíno; Sabrina Faria e Uila Gabriela (orgs.). Festival da mulher afro-latina e caribenha: mulheres negras no mercado de trabalho. Brasília: Ipea, 2012. Disponível em: www.ipea.gov.br/portal/index.php?option=com_content\&view=article\&i$d=15461$ \&ltemid=1. Acessado em 12 de novembro de 2018.

SOARES, Luiz Carlos. Rameiras, ilhoas e polacas... a prostituição no Rio de Janeiro do século XIX. São Paulo: Ática, 1992.

SOIHET, Rachel. Condição feminina e formas de violência: mulheres pobres e ordem urbana, 1890-1920. Rio de Janeiro: Forense Universitária, 1989.

SOUZA, Flávia Fernandes de. Criados, escravos e empregados: o serviço doméstico e seus trabalhadores na construção da modernidade brasileira (cidade do Rio de Janeiro, 1850-1920).Tese de Doutorado. Niterói/RJ: Instituto de Ciências Humanas e Filosofia/ Departamento de História da UFF, 2017.

Criados ou empregados? Sobre o trabalho doméstico na cidade do Rio de Janeiro no antes e no depois da abolição da escravidão. In: SIMPÓSIO NACIONAL DE HISTÓRIA: CONHECIMENTO HISTÓRICO E DIÁLOGO SOCIAL, 27. 2013, Natal. Anais... Natal: Anpuh, 2013.

- Para casa de família e mais serviço: o trabalho doméstico na cidade do Rio de Janeiro no final do século XIX. 2010. Dissertação (Mestrado em História Social) - Programa de Pós-graduação em História Social, Faculdade de Formação de Professores, Universidade do Estado do Rio de Janeiro, Rio de Janeiro. 2010.

THOMPSON, E. P. Patrícios e plebeus. In: . Costumes em comum. São Paulo: Companhia das Letras, 1998.

XAVIER, Giovana. Entre personagens, tipologias e rótulos da "diferença": a mulher escrava na ficção do Rio de Janeiro no século XIX. In: ; FARIAS, Juliana Barreto; GOMES, Flávio (org.). Mulheres negras no Brasil escravista e do pós-emancipação. São Paulo: Selo Negro, 2012. 